\title{
Malignancy-associated Hypercalcemia: role of Denosumab.
}

\author{
Angelo Michele Carella, Teresa Marinelli, Armando Melfitano, Angelo Benvenuto \\ Internal Medicine Department, T. Masselli-Mascia Hospital - 71016 San Severo (Foggia), Italy
}

\begin{abstract}
Introduction: Hypercalcemia is a common metabolic disorder in patients with malignant diseases; it is primarily associated with multiple myeloma and other hematological malignancy, but hypercalcemia is also found in advanced solid cancers, particularly squamous cell cancer as lung cancer, head and neck cancer, breast cancer, kidney and prostate cancer [1]. Frequent clinical manifestations of malignancy-related hypercalcemia are: nausea, vomiting, ileus, anorexia, dehydration, renal failure, muscle weakness, psychosis, lethargy, coma, and cardiac abnormalities as short QT interval and atrial or ventricular arrhythmia [2].

At least two main mechanisms can be responsible for hypercalcemia in these patients: humoral malignancyassociated hypercalcemia and local osteolytic hypercalcemia [3].
\end{abstract}

\section{HUMORAL HYPERCALCEMIA}

Humoral hypercalcemia of malignancy accounts for approximately $80 \%$ of hypercalcemia in cancer patients [1] and it is essentially due to tumor secretion of parathyroid hormone-related protein (PTHrP) [4] and/or tumor production of 1,25-dihydroxyvitamin D (calcitriol) [5, 6]; rarely, ectopic secretion of parathyroid hormone (PTH) has been reported [7]. PTHrP is the principal factor responsible for humoral hypercalcemia; PTHrP increases the expression of osteoblast receptor activator of nuclear factor kappa-beta ligand (RANKL) [8]. This receptor plays a central role in osteoclastogenesis and in mediating bone remodeling and resorption. Upon binding to the receptors activator of nuclear factor kappa-beta (RANK), located on the surface of osteoclast precursors and mature osteoclasts, RANKL induces both differentiation and activation of osteoclasts [9]. This in turn leads to increased bone resorption and metabolism with consequent rise of calcium plasma levels. Moreover, it has been show that PTHrP agonizes PTH receptors in renal tubular cells resulting in enhanced calcium reclamation in the kidney $[10,11]$.

\section{LOCAL OSTEOLYTIC HYPERCALCEMIA}

Local osteolytic hypercalcemia can occur as the result of osteolytic bone metastases with local release of malignancy secreted cytokines, including Tumor necrosis factor-alpha (TNF- $\alpha$ ), Transforming growth factor alpha (TGF- $\alpha$ ) and moreover Interleukin-1 (IL-1), initially termed "osteoclast activating factor"; these cytokines mediate osteoclast activation $[3,12,13]$. In addition, in local osteolytic hypercalcemia, the RANKL/RANK interaction leads to an excessive osteoclast activation resulting in enhanced bone resorption and consequent hypercalcemia [14]. In this mechanism, Transforming growth factor-beta (TGF- $\beta$ ) released as a consequence of bone resorption in the bone microenvironment, stimulating tumor growth and PTHrP expression by tumor cells, plays an important role in maintaining the "vicious cycle" between tumor cells and osteoclasts [15-17].

\section{MANGEMENT OF HYPERCALCEMIA IN CANCER PATIENTS}

Malignancy-associated hypercalcemia may become a life threatening metabolic disorder in cancer patients, so early detection and timely treatment are fundamental to prevent serious and fatal complications [2]. The optimal approach to hypercalcemia related to malignant diseases is to treat the underlying tumor; nevertheless, fluid intravenous hydration with normal saline should be the initial treatment. The hydro-saline replenishment corrects the dehydration and increases the glomerular filtration rate. Although loop diuretics inhibit renal calcium resorption, these agents should not be routinely used for all hypercalcemic patients in order not to deteriorate the dehydration; these drugs may be added after adequate fluid replenishment. Calcitonin, that inhibits bone resorption and increases the renal calcium excretion, is a useful adjunctive initial therapy. The hypocalcaemic effect of Calcitonin appears rapidly but it is often partial and temporary. Corticosteroids as Hydrocortisone and Prednisone, can prevent the conversion of precursor 25-hydroxyvitamin D into calcitriol and are useful in hypercalcemia mediated by ectopic production of calcitriol. In patients with severe renal failure and oliguria hemodialysis with a low calcium bath may be necessary [18].

Intravenous Bisphosphonates are generally established as first-line therapy after volume expansion; these agents have been widely used because of inhibitory effect of bone resorption mediated by osteoclasts. Zoledronic acid was shown to be more potent than Pamidronate in the treatment of hypercalcemia of malignancy, resulting in faster normalization of calcium plasma levels, longer maintenance of normocalcemia and longer duration of therapeutic action (about 30 days for Zoledronic acid and 20 days for Pamidronate) [19]. 
The use of intravenous Bisphosphonates is limited in patients with compromised renal function, due to druginduced nephrotoxicity; a dose reduction is required in case of glomerular filtration rate less than $60 \mathrm{ml} / \mathrm{min}$. Lastly, prolonged treatment increases the risk of rare complications such as osteonecrosis of the jaw and atypical femoral fractures [20].

\section{ROLE OF DENOSUMAB \\ IN MALIGNANCY-ASSOCIATED HYPERCALCEMIA}

From some years, in the treatment of malignancy hypercalcemia, there is a growing interest in the use of Denosumab, a human monoclonal IgG2 antibody that acts by binding with high affinity and specificity to RANKL, preventing its ligand interaction with RANK and decreasing osteoclast formation, activity and survival. By inhibiting the binding of RANKL to RANK, Denosumab significantly decreases bone resorption and hypercalcemia [21, 22]. The United States Food and Drug Administration (FDA) and the European Medicines Agency (EMA) have approved Denosumab, at dosage of $60 \mathrm{mg}$ administered as a single subcutaneous injection once every 6 months, for the treatment of osteoporosis in postmenopausal women and in men who have an increased risk of fracture; it is also approved to treat bone loss in men receiving treatment for prostate cancer that increases their risk of fracture and, FDA approval only, in women receiving adjuvant Aromatase Inhibitor therapy for breast cancer [23, 24].

At a dose of $120 \mathrm{mg}$ administered as a subcutaneous injection every 4 weeks, Denosumab is approved to prevent skeletal-related complications in patients with metastatic bone disease from solid tumors; these complications include fractures, spinal compression, or complications requiring radiotherapy or surgery. Denosumab is also approved in patients with unresectable giant cell tumor of bone; in the latter case recommended dose is $120 \mathrm{mg}$ of Denosumab administered every 4 weeks with additional $120 \mathrm{mg}$ doses on days 8 and 15 of the first month of therapy $[25,26]$. In Italy, the Italian Drug Agency (AIFA), acknowledging FDA and EMA guidances, has approved Denosumab for the same indications [27, 28]. However, in 2014, FDA has approved a new indication of Denosumab in the treatment of hypercalcemia of malignancy refractory to bisphosphonate therapy. For this indication Denosumab is administered as subcutaneous injection (120 mg) every 4 weeks, with additional doses of $120 \mathrm{mg}$ on days 8 and 15 of the first month of therapy [29].

The approval of Denosumab for hypercalcemia of malignancy was based on positive results from an open-label, single-group study of patients with advanced cancer and persistent malignancyassociated hypercalcemia after recent bisphosphonate treatment. The primary endpoint was the proportion of patients with a response, defined as an albumin-corrected serum calcium level of $11.5 \mathrm{mg} / \mathrm{dL}$ or less within 10 days after the first dose of Denosumab. The study achieved its primary endpoint with a response rate at day 10 of $63.6 \%$ in the 33 patients evaluated. The estimated median time to response was 9 days, and the median duration of response was 104 days. The most common adverse reactions were nausea, dyspnea, decreased appetite, headache, peripheral edema, vomiting, anemia, constipation, and diarrhea [30]. In clinical studies Denosumab was found to be well tolerated apart arthralgias and a risk of jaw osteonecrosis comparable to that of Zoledronate; no dose adjustment has been required in patients with renal impairment [21, 22].

\section{CONCLUSION}

Malignancy-associated hypercalcemia is a serious complication of advanced cancer. It occurs most often in patients with onco-hematological diseases and squamous cell cancer, particularly breast and renal carcinomas. Hypercalcemia of malignancy is an oncologic emergency that causes a high burden of debilitating symptoms, conveys a poor prognosis and can limit the ability to administer necessary antitumoral treatments; if left untreated, this cancer complication can lead to renal failure, progressive mental impairment, coma, and death. Denosumab, at a dose of $120 \mathrm{mg}$ every 4 weeks, recently approved by FDA for the treatment of hypercalcemia of malignancy refractory to bisphosphonate therapy, is a welcome addition that effectively inhibits osteoclast-mediated bone resorption by disrupting the RANKL/RANK pathway. It is desirable, in the near future, also in European Countries an extension of current indications of Denosumab for this potential lifethreatening cancer complication.

\section{REFERENCES}

[1] Stewart AF. Clinical practice. Hypercalcemia associated with cancer. N Engl J Med. 2005;352:373-379.

[2] Inzucchi SE. Understanding hypercalcemia. Its metabolic basis, signs, and symptoms. Postgrad Med. 2004;115(4):69-70, 73-6.

[3] Clines GA. Mechanisms and treatment of hypercalcemia of malignancy. Curr Opin Endocrinol Diabetes Obes. 2011;18:339-346.

[4] Burtis WJ, Brady TG, Orloff JJ, et al. Immunochemical characterization of circulating parathyroid hormone-related protein in patients with humoral hypercalcemia of cancer. $\mathrm{N}$ Engl $\mathrm{J}$ Med. 1990;322(16):1106-1112. 
[5] Seymour JF, Gagel RF. Calcitriol: the major humoral mediator of hypercalcemia in Hodgkin's disease and non-Hodgkin's lymphomas. Blood. 1993;82(5):1383-1394.

[6] Donovan PJ, Sundac L, Pretorius CJ, et al. Calcitriol-mediated hypercalcemia: causes and course in 101 patients. J Clin Endocrinol Metab. 2013;98(10):4023-4029.

[7] Galindo RJ, Romao I, Valsamis A, et al. Hypercalcemia of Malignancy and Colorectal Cancer. World J Oncol. 2016;7(1):5-12.

[8] Budayr AA, Nissenson RA, Klein RF, et al. Increased serum levels of a parathyroid hormone-like protein in malignancy-associated hypercalcemia. Ann Intern Med. 1989;111(10):807-812.

[9] Orloff JJ, Wu TL, Stewart AF. Parathyroid hormone-like proteins: biochemical responses and receptor interactions. Endocr Rev. 1989;10(4):476-495.

[10] Bender RA, Hansen H. Hypercalcemia in bronchogenic carcinoma. A prospective study of 200 patients. Ann Intern Med. 1974;80(2):205-208.

[11] Law F, Ferrari S, Rizzoli R, et al. Parathyroid hormone-related protein and calcium phosphate metabolism. Pediatr Nephrol. 1993;7(6):827-33.

[12] Roodman GD. Mechanisms of bone metastasis. N Engl J Med. 2004;350(16):1655-1664.

[13] Mundy GR, Raisz LG, Cooper RA, et al. Evidence for the secretion of an osteoclast stimulating factor in myeloma. New Engl J Med. 1974;291(20):1041-1046.

[14] Clines GA, Guise TA. Hypercalcemia of malignancy and basic research on mechanisms responsible for osteolytic and osteoblastic metastasis to bone. Endocr Relat Cancer. 2005;12(3):549-583.

[15] Yin JJ, Selander K, Chirgwin JM, et al. TGF-beta signaling blockade inhibits PTHrP secretion by breast cancer cells and bone metastases development. J Clin Invest. 1999;103:197-206.

[16] Mundy GR. Mechanisms of bone metastasis. Cancer. 1997;80:1546-1556.

[17] Kakonen SM, Mundy GR. Mechanisms of osteolytic bone metastases in breast carcinoma. Cancer. 2003;97:834-839.

[18] Rosner MH, Dalkin AC. Onco-nephrology: the pathophysiology and treatment of malignancy-associated hypercalcemia. Clin J Am Soc Nephrol. 2012;7:1722-1729.

[19] Major P, Lortholary A, Hon J, et al. Zoledronic acid is superior to pamidronate in the treatment of hypercalcemia of malignancy: a pooled analysis of two randomized, controlled clinical trials. J. Clin. Oncol. 2001;19(2):558-567.

[20] Watts NB, Diab DL. Long-term use of bisphosphonates in osteoporosis. J Clin Endocrinol Metab. 2010;95(4):1555-65. doi: 10.1210/jc.2009-1947.

[21] Castellano D, Sepulveda JM, García-Escobar I, et al. The role of RANK-ligand inhibition in cancer: the story of denosumab. Oncologist. 2011;16:136-145.

[22] Perez Ruixo JJ, Doshi S, Sohn W, et al. Quantitative pharmacology of denosumab in patients with bone metastases from solid tumors. J Clin Pharmacol. 2015;55 Suppl 3:S85-92. doi: 10.1002/jcph.388.

[23] https://www.accessdata.fda.gov/drugsatfda_docs/label/2016/125320s178lbl.pdf

[24] http://www.ema.europa.eu/ema/index.jsp?curl=pages/medicines/human/medicines/001120/human_med_ 001324.jsp\&mid=WC0b01ac058001d124

[25] https://www.accessdata.fda.gov/drugsatfda_docs/label/2013/125320s094lbl.pdf

[26] http://www.ema.europa.eu/docs/en_GB/document_library/EPAR_Product_Information/human/002173/ WC500110381.pdf

[27] https://farmaci.agenziafarmaco.gov.it/aifa/servlet/PdfDownloadServlet?pdfFileName=footer_002317_04 0108_RCP.pdf\&retry=0\&sys=m0b113

[28] https://farmaci.agenziafarmaco.gov.it/aifa/servlet/PdfDownloadServlet?pdfFileName=footer_002317_04 1300_RCP.pdf\&retry=0\&sys=m0b113

[29] https://www.accessdata.fda.gov/drugsatfda_docs/appletter/2014/125320orig1s160ltr.pdf

[30] Hu MI, Glezerman IG, Leboulleux S, et al. Denosumab for Treatment of Hypercalcemia of Malignancy. J Clin Endocrinol Metab. 2014;99(9):3144-3152. doi: 10.1210/jc.2014-1001 